\title{
Interactive Information Dissemination System (IIDS) - An Innovative ICT Model for Agro Advisory Services to the Indian Farmers
}

\author{
B. Savitha ${ }^{1^{*}}$, D. Raji Reddy ${ }^{1}$, T.S. Anurag ${ }^{2}$, P. Sailu ${ }^{2}$ and M. Mahadevaiah ${ }^{2}$ \\ ${ }^{1}$ Division of Extension, Professor Jayashankar Telangana State Agricultural University, \\ Hyderabad, Telangana, India \\ ${ }^{2}$ Digital India Corporation, New Delhi, India \\ *Corresponding author
}

A B S T R A C T

'Interactive Information Dissemination System (IIDS)' is an innovative ICT model to address the information needs of the Indian farmers. This ICT tool was designed and

Keywords

IIDS, Information needs, ICT in Agriculture, State Agricultural Universities

Article Info

Accepted:

16 August 2018

Available Online:

10 September 2018 developed under a project awarded by Indian Council of Agricultural Research under National Agricultural Innovation Project (NAIP). The IIDS is now being up scaled in three states. It is a multi-platform and multi-mode application. The unique feature of this model is, it enable the scientists to provide personalized advisories based on the farm and farmer profile in the areas of agriculture, horticulture, animal husbandry and fisheries. Farmer can record their queries $24 \times 7$ through Toll Free Number. Farmers are provided with Text and Voice messages in local language (Telugu) and provides platform for direct interaction with Scientists. This model also facilitated the Scientists of the University to provide alert and emergency messages on their mobile. The impact of IIDS envisaged shift in the Source of Information from friends \& neighbors and Input dealers to Scientists. The IIDS has got vast scope for up scaling in all State Agricultural Universities in India to enhance outreach.

\section{Introduction}

This IIDS is an integrated model based on the study and analysis of 26 major ICT Initiatives in agriculture in India. This model is largely integration of Toll free IVRS, Smart Phone Application and Web based agricultural advisory system. The major limitation in current information dissemination system i.e., call center, IVRS system and mobile services are lack of database of farmers, such as location of the farmer, type of field, crops grown, status of the farmer, need of the farmer and other demographic and agriculture profile. Thus, in the proposed system each farmer have to register himself by providing certain details which would be stored in the database and a profile and requirement (need) of each farmer would be recorded. The agricultural expert would provide the personalized solution based on the inputs provided by the farmers and his available profile. Also this system would allow farmers to send text, voice, images and video of the field along with their queries by using a smart phone. 
This system would be helpful in addressing farmers' information need on important aspects including agriculture technology, crops / plant protection, weather information, market prices, government schemes etc. in location specific manner.

\section{USP of IIDS Model}

Personalized 'Agro Advisory' Based on 'Farm and Farmer Profile'.

Live Interaction with Scientists over toll free number

Facility to 'Refer Critical Problems' to relevant 'Crop Specialist' available virtually

'Round the Clock Query Registration Facility' through IVRS \& Smart Phones

'Anywhere Anytime Access' on Past Advisories

Facility to 'Push Emergency Message' to Farmers based on Location and Crops

'Network Independent' - Accessible from All Networks

\section{IIDS applications and its features}

It is an integrated system with a combination of Web, IVRS and Mobile Application Technologies for dissemination of farm and farmer specific advises/information at user desired mode and time. The major applications are - IVRS based application, Mobile based application and Web based application. The major features are as follows:

IVRS based application (Toll free number: 18004253141 )

Live interaction with Scientists

Call recording facility in case if the experts are not available.

Intelligent enough to route the call to the relevant experts.

Listen back previous advisory

Recording and listening the farmers' best practices/experiences

Facilitate the farmers for getting Market, Weather and Govt. Schemes related information

Call back facility for Expert to get the feedback from the farmer

$24 \times 7$ query registration facility for farmers

\section{Mobile application for smart phones (UMANG-AKPS)}

Facility to call directly to toll free number

Multimedia query (text, voice, image and video)

Refer questions \& answers

View of text and voice messages

Manage services

Refer best practices from the concerned district

Un-registered farmer can able to register his details

AKPS App available under UMANG (Unified Mobile Application for New age Governance) App

\section{Web based application (www.akps.in)}

Colour coded iconic based logins for various type of users 
Expert support system linked with authentic content / information service providers.

Information dissemination and aggregation system (multimodal)

Centralized common database for web, mobile \& IVRS applications

Facility to know the farmer feedback about expert advisory

Facility provided to activate the inactive/passive farmers

Reports and analytics

Services offered to the farmers through IIDS

The IIDS model is useful in enhancing the extension outreach through KVKs and DAATTCs. The implementation of IIDS has elevated the image of the Professor Jayashankar Telangana State Agricultural University (PJTSAU) extension in terms of increased direct interaction of farmers with scientists over toll free number, dissemination of farm information through mobiles (text and voice messages in Telugu) and Annapurna information corners, functional linkages among the Department of Agriculture, Horticulture, Animal Husbandry and Fisheries and Indian Council of Agricultural Research (ICAR) institutes

Farmers are being provided personalized advice on Agriculture, Horticulture, Animal Husbandry and Fisheries from their Krishi Vigyan Kendra (KVK)/ District Agricultural Advisory and Transfer of Technology Centre (DAATTC) on Toll Free number (1800-4253141).

Farmer can record their queries $24 \times 7$ through Toll Free Number.
Farmers are provided with Text \& Voice messages in local language (Telugu).

Farmers are provided emergency messages and alerts on their mobile from Krishi Vigyan Kendra (KVK)/District Agricultural Advisory and Transfer of Technology Centre (DAATTC).

As a joint initiative of PJTSAU and Digital India Corporation (Formerly Media Lab Asia), the IIDS is being up scaled in all the districts of Telanagana through KVKs/DAATTCs.

\section{Benefits to Farmers}

Farmers are able to talk to the Scientists directly over a mobile phone with Toll free number.

Farmers are receiving text as well as voice messages on their mobiles in local language

Farmers are using the text messages as Reference and showing to the input dealers to get the right pesticide from the shop.

Timely information helped in reducing no. of sprays/application of excessive use of fertilizers etc.

Illiterate farmers are also comfortable in receiving messages, since information is given through voice messages.

Messages related to production, protection, post-harvest and weather are sent to the mobiles of farmers.

The weather forecasts helped the farmers, to avoid the unnecessary irrigations before rains, postponing of crop harvests etc.

Short films are loaded in the mobiles of project farmers thereby farmers are accessible to the information with multimedia experience. 
Reduced production cost

Increased awareness about use of ICTs in agriculture.

At present, the IIDS is being up scaled in all the districts of Telanagana through KVKs/DAATTCs. 15,712 registered farmers are being served, 518 mandals, 2191 villages covered, 1721 text messages and 579 voice messages sent through IIDS. Text and voice messages are sent particularly on pest and disease management, fertilizer management, seeds and sowing, seed availability, weather alerts and weather based agro-advisories, crop contingency measures, market information and government schemes etc pertaining to Agriculture and Horticulture; vaccination, breeding, health management, deworming, artificial insemination fodder production, etc pertaining to Animal Husbandry and selection of suitable species, water management in ponds/tanks, feed management, disease management, dissolved oxygen management, supplementary feeds, post-harvest handling etc pertaining to Fisheries.

In view of the vast scope of IIDS services, it is recommended to be replicated in other states of India especially by the State Agricultural Universities and departments of agriculture.

\section{Perception of farmers about the services rendered through IIDS}

While interviewing the respondents regarding the perception of IIDS, 98.0 per cent of the respondents agreed that IIDS service is giving clear information on the subjects they required 91.7 per cent of the respondents agreed that IIDS service is providing the farmers with timely information and 98.3 per cent of the respondents agreed that information provided by IIDS service is easily understandable. Scientist-Farmer interaction programme was appreciated by 66.2 per cent of the respondents.
Only 46.4 per cent respondents agreed Field diagnostic visit is useful. Since they didn't get much exposure on the same.

The interaction between the innovative farmers and other farmers has been accepted as a useful system by 69.3 per cent of the respondents.

Majority of the respondents informed that usage of chemical fertilizer (88.8 per cent respondent) and pesticides (91 per cent respondent) has been reduced due to the fertilizer and pesticide management information provided by the IIDS model.

The shift in the 'Source of Information is found among the IIDS farmers and it was noted that 92 per cent farmers who were earlier dependent for agricultural information on their friends \& neighbor is reduced to 56 per cent and 68.7 per cent farmers who were dependent on Input dealers is reduced to 35 per cent due to the provision given to the farmers to direct interact with the KVK/DAATTC Scientists on Toll Free number.

\section{Success stories}

\section{Kurlepu Prabhu, Rampur village, Kotagiri Mandal, Nizamabad District}

ID: 17185160, Mobile number: 80963 61881, no. of calls made: 30

He has registered in IIDS through Krishi Vigyan Kendra (KVK), Rudrur, Nizamabad district. He has utilized services very effectively by calling Scientists regarding various crop production and protection activities and timely measures to be followed especially in Paddy.

His queries included fertilizer management, control of stem borer, brown plant hopper and 
blast in paddy where timely advisories received from the Scientists and effective implementation helped him reap benefits with cost reduction towards the plant protection measures and fertilizers consumption. He also sought the information regarding availability of quality seed of crops like, Paddy, Sesame, Green Gram and Bengalgram (Fig. 1-4).

Fig.1 IIDS Framework

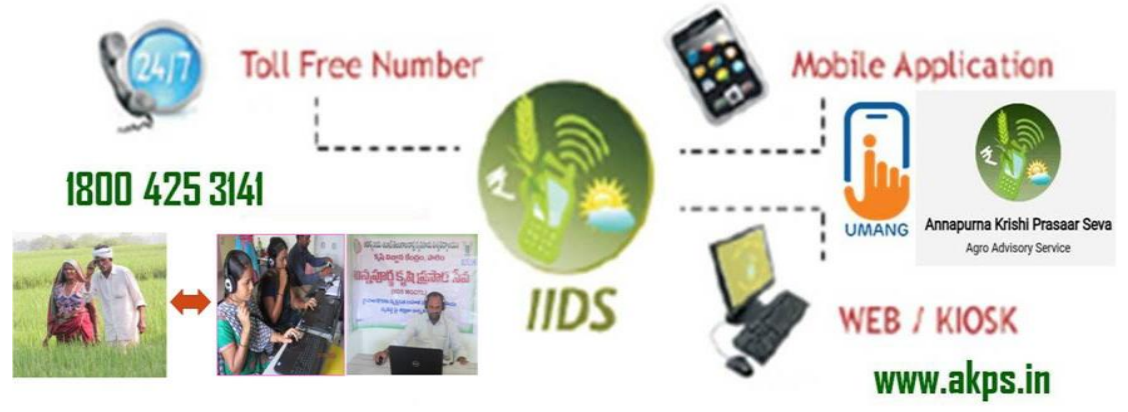

Fig.2 Perception about the IIDS Model

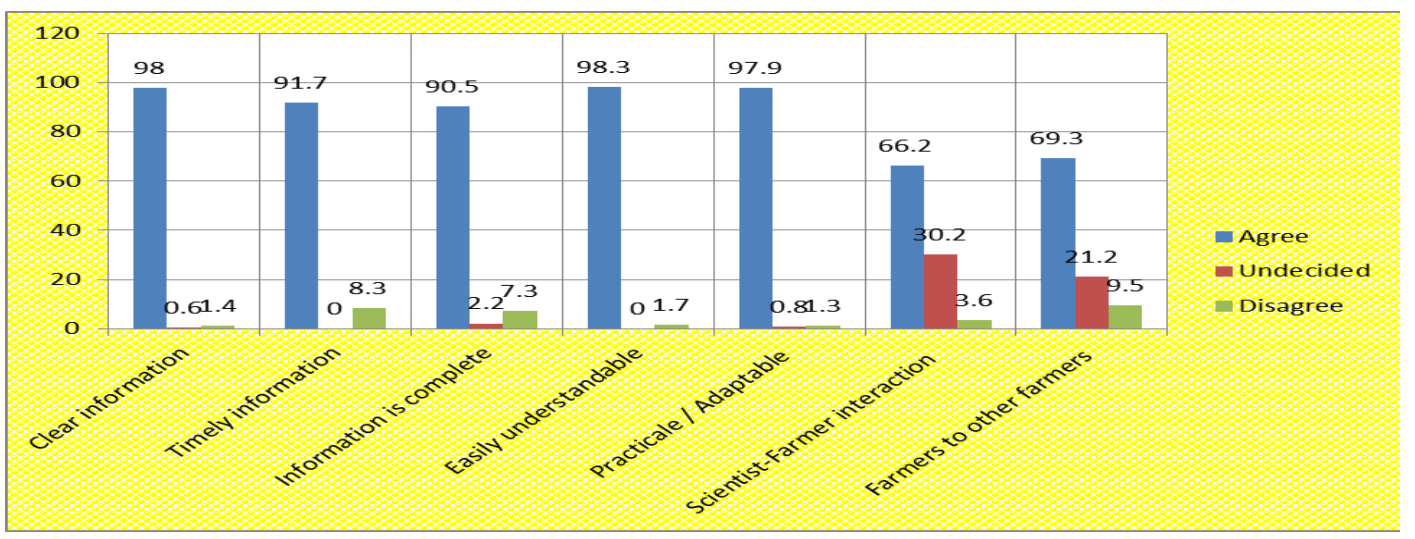

Fig.3 Progress in Agriculture due to the IIDS service

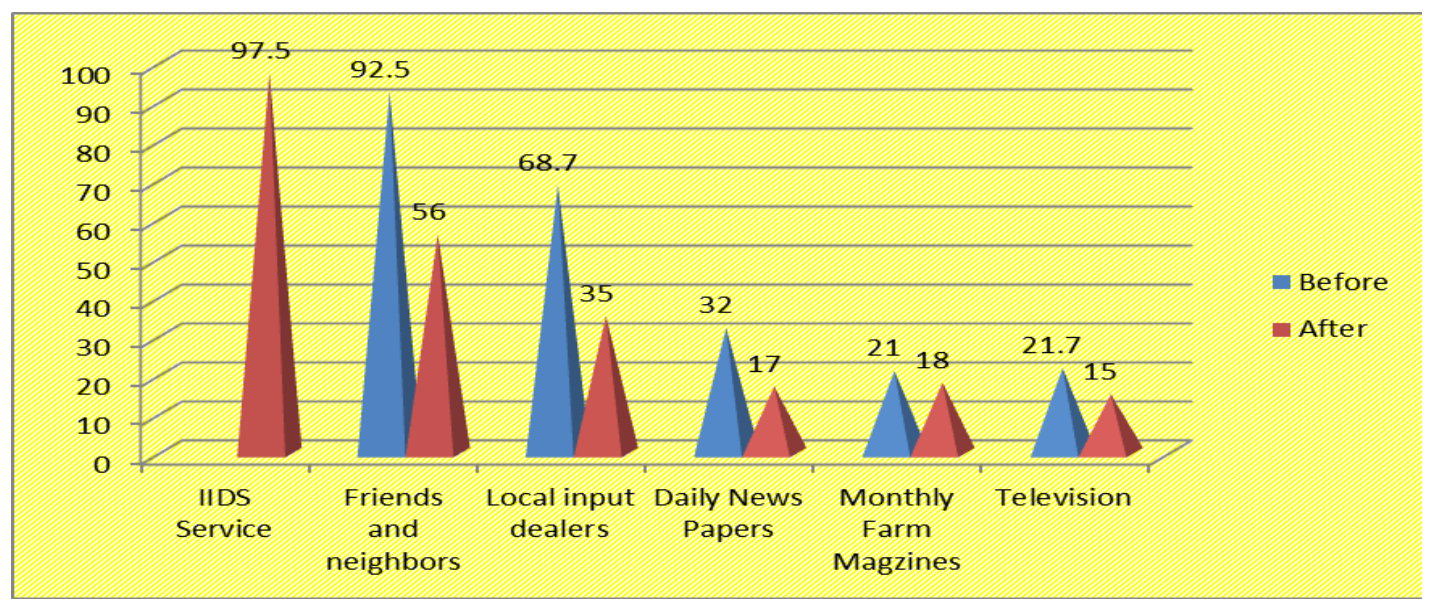


Fig.4 Source of Farm Information before and after the initiation of the IIDS service

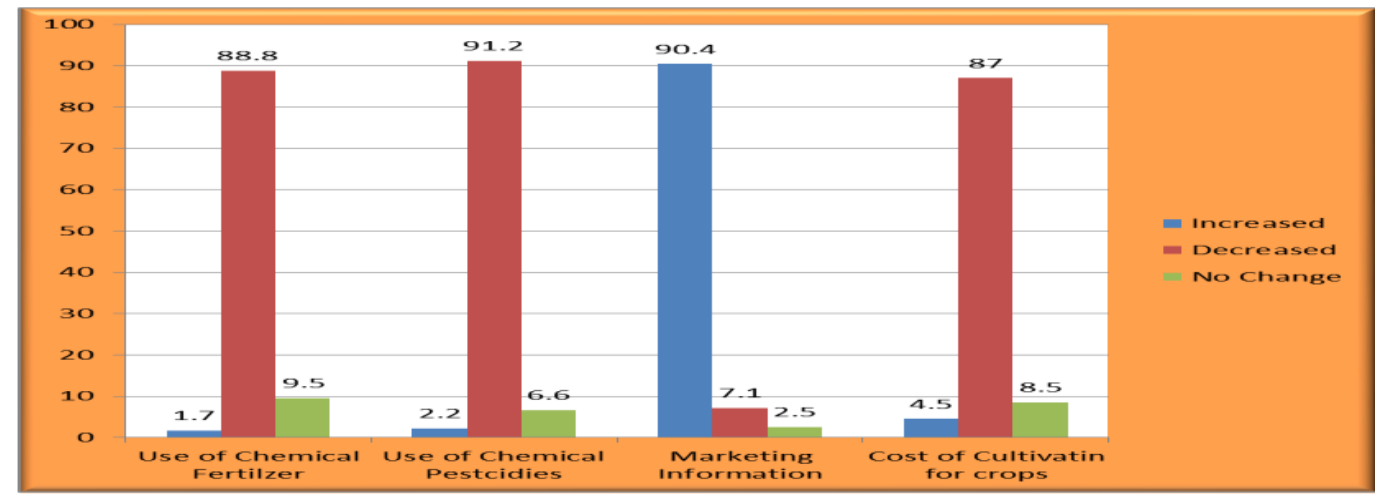

The information received on importance of alleyways in paddy, soil test based fertilizer management and its importance in soil health management, judicious application of pesticides enabled him attain 1.5 to 2.5 quintal of higher yields than earlier with cost savings upto Rs.2,500/- per acre.

\section{Vikas Babu, Lokavaram village, Kallur Mandal, Khammam District}

ID: 10106665, Mobile number: 8008258682 , no. of calls made: 41

He has registered in IIDS through Krishi Vigyan Kendra (KVK), Wyra, Khammam district. Before the IIDS, he was mostly dependent on input dealers and neighbor farmers for information. Now, with the help of IIDS toll free number getting the agro advisories and suggestions from KVK experts.

His queries included the advisories on blast, $\mathrm{BPH}$ management, fertilizer management, correction of micro nutrient deficiencies, nursery management, drum seeder technology, suitable high varieties for kharif and rabi seasons in Rice crop and sucking pest management in Cotton etc. He expressed that, alert messages (text and voice) related to local specific crop problems and weather information provided to his mobile, are very useful in taking up timely control measures and reduced unnecessary investment on pest management.

\section{Husya Naik, Turuputhanda Village, Damarcherla Mandal, Nalgonda District}

ID: 76208990, Mobile number: 9642450240 , No. of calls made: 46

He has registered in IIDS through Krishi Vigyan Kendra (KVK), Kampasagar, Nalgonda district. His queries included pest \& disease management, fertilizer management, seed treatment chemicals, weather information etc. He has used the text messages as reference to buy the pesticide from dealers shop.

The information received on pest $\&$ disease management in rice cultivation enabled him attain 6 bags higher yield than earlier with cost savings upto Rs. 3,500/- per acre with net benefit of Rs.8,000/- per acre.

\section{P. Kashanna, Kummera Village, Thadur Mandal, Mahabubnagar District}

ID: 24336565, Mobile number: 9440166676, no. of calls made: 23

He has registered in IIDS through Krishi Vigyan Kendra (KVK), Palem, 
Mahabubnagar district. His queries included pest and disease management, fertilizer management, varieties etc. He has used the text messages as reference to buy the pesticide from dealers shop. Voice and text messages are helped him in taking up timely $\&$ needy measures in rice crop. This enabled him to reduce pesticide sprayings (from 6 to 3) with cost savings upto Rs. 6,000/- and yield advantage of 5 quintals per acre.

Extension remains a valued service throughout the world. Agricultural extension has been defined as a series of embedded communicative interventions which help resolution of problematic situations face by the farmers. Extension is increasingly being asked to do more with less and most of the organizations are responding to this challenge by extending the reach of information through ICT.

The concept of IIDS is very relevant to the agricultural extension functionaries. The information dissemination through Multimedia (Text, Voice, Image and Video) is very appreciable. IIDS is can be a better alternative ICT model to the farmers because; from field itself farmer can interact directly with the scientists. The personalized advisories to the farmers are more appreciable in this model as the scientist can refer the farm profile and history before providing the solution. It will be a good monitoring tool to the scientists of KVKs/DAATTCs to monitor the farmer's field and it will be a good knowledge management system for knowledge providers and policy makers.

\section{References}

Anurag TS, Punna Rao P, Madhavarao, and Arbind Simha 2014, Final IIDS Project report submitted to the NAIP, ICAR, New Delhi.

Gidda Reddy P, Punna Rao P, Aruna Sri I and Mallika M 2011, Effectiveness of ICT initiatives in Agriculture. Indian Journal of Agricultural Library and Information Services, Vol. 27(1), Page No.63-70.

Gidda Reddy P, Punna Rao P, Mallika M and Aruna Sri I 2011, Information needs of farmers. Indian Journal of Agricultural Library and Information Services, Vol. 27(2), Page No. 25-30.

Gidda Reddy., Punna Rao, P. Mallika, M. and Aruna Sri, I. 2011, Farmer's perception on usefulness of ICT initiatives in Agriculture. Journal of Agricultural Extension Management. Vol.XII, No.1, January-June, page No. 37-47.

Punna Rao P, Raja Reddy K, Anurag TS, Mahadevaiah M and Sailu P (2017). Interactive information dissemination system (IIDS) - An Alternative I.C.T model to meet the information needs of Indian farmer, Journal of Pharmacognosy and Phytochemistry, Special Issue, Page No. 314-318.

\section{How to cite this article:}

Savitha, B., D. Raji Reddy, T.S. Anurag, P. Sailu and Mahadevaiah, M. 2018. Interactive Information Dissemination System (IIDS) - An Innovative ICT Model for Agro Advisory Services to the Indian Farmers. Int.J.Curr.Microbiol.App.Sci. 7(09): 2274-2280. doi: https://doi.org/10.20546/ijcmas.2018.709.282 